\title{
Economic Growth and Cardiorespiratory Fitness of Children and Adolescents in Urban Areas: A Panel Data Analysis of 27 Provinces in China, 1985-2014
}

\author{
Xiaomei Gan ${ }^{1}$, Xu Wen ${ }^{1,2}$, Yijuan $\mathrm{Lu}^{1}$ and Kehong Yu ${ }^{1,2, *}$ \\ 1 Department of Sport Science, College of Education, Zhejiang University, Hangzhou 310000, China; \\ 11603020@zju.edu.cn (X.G.); wenxu@zju.edu.cn (X.W.); 11703023@zju.edu.cn (Y.L.) \\ 2 Center for Sports Modernization and Development, Zhejiang University, Hangzhou 310000, China \\ * Correspondence: yukh@zju.edu.cn; Tel.: +86-571-8827-3031; Fax: +86-571-8827-3187
}

Received: 1 September 2019; Accepted: 3 October 2019; Published: 8 October 2019

\begin{abstract}
With rapid economic development in China, cardiorespiratory fitness (CRF) of children and adolescents is on a decline. However, this appears to have slowed down, reaching stagnation in certain areas. However, it is unclear if the change in CRF is related to economic growth and development or not. This study describes trends in CRF of Chinese children and adolescents, and empirically tests the relationships between China's macro-economic developments and cardiorespiratory fitness of children and adolescents over the past 30 years using provincial panel data collected from one million samples. We used per capita disposable income as the economic indicator. CRF was assessed by using running tests: $50 \mathrm{~m} \times 8$ for boys and girls (7-12 years), $1000 \mathrm{~m}$ for boys (13-22 years), and $800 \mathrm{~m}$ for girls (13-22 years). The results show that economic growth has a U-shaped relationship with CRF of children and adolescents (both boys and girls). It appears that as incomes increased, CRF of urban male and female students in China gradually decreased to its lowest point, after which it showed an upward trend. From a horizontal perspective, it can be inferred that for low-developed provinces, increases in incomes cause a decrease in CRF levels. In contrast, for highly developed provinces, as incomes increase, CRF levels increase. This study provides the first empirical evidence of the relationship between macro-economy and CRF of youth, based on provincial panel data. The results presented here can be used to formulate health policies targeting the cardiorespiratory fitness of children and adolescents from middle-income provinces in China. This study also provides a reference for developing countries.
\end{abstract}

Keywords: children and adolescents; economic growth; cardiorespiratory fitness; relationship

\section{Introduction}

Low cardiorespiratory fitness (CRF) is a strong and independent predictor of cardiovascular disease [1], cancer [2], and diabetes [3]. A previous study reported that global physical activity is on a decline [4]. In recent decades, the US, Canada, France, Australia, Italy, South Korea, Finland, and Norway, among other countries, have witnessed a significant decrease in cardiorespiratory fitness of children and adolescents [5-8]. Sedentary lifestyles and lack of physical activity are thought to be the main causes for this decline [9,10]. Moreover, social-economic environments, technology development, urbanization, and urban development influence CRF more than other public health factors [11,12].

A cross-sectional study on cardiorespiratory fitness in children and adolescents from several countries concluded that there is a strong negative correlation between national income inequality (GiNi index) and CRF of children and adolescents [13,14]. In low- and middle-income countries, high urbanization and incomes are risk factors for chronic cardiovascular related-diseases [15]. However, 
the growth of national economies has altered the relationship between urbanization and individual physical activity. For example, from 1991 to 2009, the level of physical activity of individuals living in highly urbanized areas in China was lower than that of those living in less-urbanized areas. However, research has revealed that this difference diminishes with rise in incomes in less-urbanized areas [15]; intensive construction of residential buildings [16], sports facilities, and transportation facilities [17] also contributes to this change.

Previous studies have explored the impact of socio-economic development on physical activity and cardiopulmonary function, primarily using cross-sectional data. Due to the lack of time series data, the impact of various CRF factors has not been tested. Moreover, few studies have investigated CRF from the perspective of socio-economic development. Although China's economy has grown rapidly over the past 30 years, the country is facing several challenges, especially in the social security, and medical and health sectors, which require new reforms and policies to improve the health of the population. Based on panel data from 27 provinces in China collected over the past 30 years, this study analyzed the CRF of one million children and adolescents aged 7 to 22 years. The authors aimed to describe the trends in CRF of children and adolescents, evaluate the impact of rapid development of social economy on CRF using provincial panel data, and explore the relationship between economic development and CRF of children and adolescents in a developing country. To the best of our knowledge, this perspective has not been reported before. Our results provide empirical evidence of the association between economy and children's CRF, and explore the impact of economy on students' CRF. These findings provide a scientific basis for policy formulation and effective intervention, and also serve as a reference for developing countries.

\section{Method}

\subsection{Data}

\subsubsection{CRF Data}

CRF data were derived from the Chinese National Surveys on Students' Constitution and Health (CNSSCH) conducted in 1985, 1991, 1995, 2000, 2005, 2010, and 2014 [18-24]. These series of surveys were conducted by the Ministries of Education, Health, Science and Technology; the State Ethnic Affairs Commission; and the State Sports General Administration of the People's Republic of China. This study only included students of Han ethnicity, which constitutes $92 \%$ of the total Chinese population. The respondents were from 27 of the 31 provinces in China, excluding Hainan and Chongqing, both of which were founded after 1985. Qinghai and Tibet autonomous regions were also excluded because Qinghai was not included in the 1995 survey and Tibet autonomous region was not covered in nearly all surveys. Each study enrolled an equal number of students from each province. The participants were aged 7-22 years (primary to college level), and were selected from the same areas in each province from 1985 to 2014. The students were selected using the stratified cluster sampling method from certain classes, and clusters were randomly selected from each grade in the selected schools. Cardiorespiratory fitness was assessed using running tests: $50 \mathrm{~m} \times 8$ for girls and boys aged 7-12 years, $1000 \mathrm{~m}$ for boys aged 13-22 years, and $800 \mathrm{~m}$ for girls aged 13-22 years. Table 1 shows the sample sizes at each examination period. The research protocol was reviewed and approved by the Ethics Committee of College of Education at Zhejiang University. 
Table 1. Sample Sizes at Each Examination Period in CNSSCHA (Aged 7-22 years), 1985-2014.

\begin{tabular}{|c|c|c|c|c|c|c|c|c|c|c|c|c|c|c|}
\hline \multirow{2}{*}{ Age } & \multicolumn{7}{|c|}{ Male } & \multicolumn{7}{|c|}{ Female } \\
\hline & 1985 & 1991 & 1995 & 2000 & 2005 & 2010 & 2014 & 1985 & 1991 & 1995 & 2000 & 2005 & 2010 & 2014 \\
\hline 7 & 8560 & 2933 & 4401 & 3051 & 4935 & 4486 & 4464 & 8559 & 2925 & 4400 & 4512 & 4860 & 4481 & 4480 \\
\hline 8 & 8561 & 2999 & 4398 & 4446 & 4934 & 4485 & 4489 & 8561 & 2977 & 4406 & 4533 & 4862 & 4469 & 4487 \\
\hline 9 & 8557 & 2959 & 4397 & 4546 & 4945 & 4481 & 4478 & 8561 & 2951 & 4402 & 4494 & 4892 & 4490 & 4490 \\
\hline 10 & 8557 & 2932 & 4390 & 4571 & 4916 & 4490 & 4485 & 8559 & 2942 & 4402 & 4657 & 4932 & 4487 & 4488 \\
\hline 11 & 8561 & 2965 & 4396 & 4587 & 5051 & 4500 & 4487 & 8559 & 2935 & 4413 & 4498 & 4894 & 4496 & 4474 \\
\hline 12 & 8558 & 2957 & 4398 & 4524 & 4917 & 4483 & 4479 & 8557 & 2875 & 4397 & 4518 & 4785 & 4484 & 4477 \\
\hline 13 & 8558 & 2906 & 4394 & 4523 & 4914 & 4487 & 4487 & 8558 & 2933 & 4395 & 4530 & 4925 & 4487 & 4495 \\
\hline 14 & 8560 & 2948 & 4403 & 4546 & 4852 & 4489 & 4487 & 8561 & 2931 & 4383 & 4513 & 4859 & 4494 & 4485 \\
\hline 15 & 8556 & 2952 & 4403 & 4561 & 4979 & 4489 & 4482 & 8556 & 2924 & 4394 & 4516 & 4935 & 4482 & 4489 \\
\hline 16 & 8559 & 2936 & 4343 & 4551 & 4892 & 4476 & 4481 & 8557 & 2911 & 4396 & 4519 & 4916 & 4454 & 4493 \\
\hline 17 & 8532 & 2936 & 4395 & 4507 & 4919 & 4488 & 4494 & 8537 & 2910 & 4403 & 4524 & 4857 & 4485 & 4490 \\
\hline 18 & 8324 & 2968 & 4335 & 4549 & 4979 & 4476 & 4289 & 8159 & 2933 & 4365 & 4632 & 5047 & 4435 & 4289 \\
\hline 19 & 5516 & 2937 & 2850 & 3302 & 3777 & 2971 & 2973 & 5551 & 2988 & 2863 & 3449 & 3938 & 2996 & 2997 \\
\hline 20 & 5593 & 2953 & 2876 & 3181 & 3741 & 2975 & 2970 & 5580 & 2968 & 2880 & 3306 & 3905 & 2982 & 2988 \\
\hline 21 & 5592 & 2770 & 2875 & 3187 & 3744 & 2972 & 2989 & 5462 & 2751 & 2879 & 2958 & 3752 & 2986 & 2987 \\
\hline 22 & 4332 & 2955 & 2829 & 2718 & 3327 & 2915 & 2865 & 3335 & 2685 & 2737 & 2555 & 3390 & 2917 & 2881 \\
\hline Total & 123,476 & 47,006 & 64,083 & 65,350 & 73,822 & 65,663 & 65,399 & 122,212 & 46,539 & 64,115 & 66,714 & 73,749 & 65,625 & 65,490 \\
\hline
\end{tabular}




\subsubsection{Socioeconomic Data}

The data of per capita disposable income (PCDI) were derived from the respective statistical yearbooks of China's provinces $(1985,1991,1995,2000,2005,2010$, and 2014) and the statistical database of the Chinese economic network [25].

\subsection{Variables}

To overcome heteroscedasticity and enhance the stationarity of data, the logarithm of all variables was used [26]. The dependent variables were L50 $\times 8$, L1000 and L800, which was the log of the student's running test time of $50 \mathrm{~m} \times 8,1000 \mathrm{~m}$, and $800 \mathrm{~m}$. As the core independent variable, PCDI served as the economic indicator. The control variables were urbanization rate (URBAN) and consumer price index (CPI). Considering that urbanization correlates with physical activity [14,15], the rate of urbanization was used to determine its impact on CRF. In addition, over-nutrition was associated with a decreased cardiorespiratory endurance level [27]; thus, CPI was utilized to assess the indirect impact of nutrition on CRF. Table 2 illustrates the variables used in this study.

Table 2. Summary Statistics of all Variables.

\begin{tabular}{cccccc}
\hline Variable & Observations & Mean & S.D. & Min & Max \\
\hline $50 \mathrm{~m} \times 8$ (Both) & 2268 & 123.63 & 10.28 & 95.66 & 184.82 \\
$50 \mathrm{~m} \times 8$ (Male) & 1134 & 121.23 & 10.26 & 95.66 & 184.82 \\
$50 \mathrm{~m} \times 8$ & 1134 & 126.03 & 9.72 & 102.73 & 184.79 \\
$($ Female $)$ & 1890 & 258.09 & 19.72 & 216.73 & 348.15 \\
$1000 \mathrm{~m}$ & 1890 & 252.27 & 16.31 & 202.65 & 320.93 \\
$800 \mathrm{~m}$ & 6048 & 9696.99 & 9769.57 & 510.14 & $47,758.17$ \\
PCDI & 6048 & 40.82 & 18.13 & 11.48 & 89.6 \\
URBAN & 6048 & 105.72 & 5.89 & 97.9 & 121.4 \\
CPI & 2268 & 4.81 & 0.08 & 4.56 & 5.22 \\
\hline L50 $\times 8$ (Both) & 1134 & 4.79 & 0.08 & 4.56 & 5.22 \\
L50 $\times 8$ (Male) & 1134 & 4.83 & 0.08 & 4.63 & 5.22 \\
L50 $\times 8$ & 1890 & 5.55 & 0.08 & 5.38 & 5.85 \\
$($ Female $)$ & 1890 & 5.53 & 0.06 & 5.31 & 5.77 \\
L1000 (Male) & 6048 & 8.55 & 1.24 & 6.23 & 10.77 \\
L800 (Female) & 6048 & 3.6 & 0.48 & 2.44 & 4.5 \\
LPCDI & 6048 & 4.66 & 0.05 & 4.58 & 4.8 \\
LURBAN & & & \\
LCPI & &
\end{tabular}

PCDI, real per capita disposable income; URBAN, urbanization rate; CPI, consumer price index; L50 $\times 8, \log$ of $50 \mathrm{~m}$ $\times 8$; L1000, $\log$ of $1000 \mathrm{~m}$; L800, $\log$ of $800 \mathrm{~m}$; LPCDI, $\log$ of real PCDI; LURBAN, log of URBAN; LCPI, $\log$ of CPI.

\subsection{Estimation Approach}

Panel econometric models were employed to estimate the relationship between students' CRF status and PCDI. To reduce endogeneity and increase the scientific soundness of the model, several control variables were introduced. The models used are as follows:

Equation (1) is used to estimate the relationship between economic development and the students' CRF. Empirical analysis of the static model was performed using Stata 12.0 software (StataCorp, College Station, Texas, USA):

$$
\mathrm{LY}=\alpha+\beta_{1} \times \mathrm{LPCDI}+\beta_{2} \times \mathrm{LURBAN}+\beta_{3} \times \mathrm{LCPI}+\mathrm{t}+\varepsilon
$$

where LY is log of the CRF status of students at each age in each province and survey, LPCDI is the log of economic level of each province and survey, LURBAN stands for log of urbanization rate of each province and survey, and LCPI represents the log of the consumer price index of each province and survey. LURBAN and LCPI are control variables that are expected to be related to the CRF status, $\alpha$ 
represents the fixed effects of a province, $\mathrm{t}$ is the time-specific effects, and $\varepsilon$ is the error term. These equations employ the fixed effect regression model, which controls for time-invariant characteristics, such as climatic conditions and unmeasured cultural factors, and any time-varying differences common to all provinces.

Equation (2) is the quadratic model used to investigate the marginal effect of economic growth on the students' CRF, that is, to verify whether a non-linear relationship exists between the two:

$$
\mathrm{LY}=\alpha+\beta_{1} \times \mathrm{LPCDI}+\beta_{2} \times \mathrm{LPCDI}^{2}+\beta_{3} \times \mathrm{LURBAN}+\beta_{4} \times \mathrm{LCPI}+\mathrm{t}+\varepsilon
$$

\section{Results}

\subsection{Secular Trends in CRF from 1985 to 2014}

The secular trends of mean CRF test time for boys and girls from 1985 to 2014 are shown in Table 3. The surveys focused on 7, 13,16, and 19-year-old students as the specific ages for first-grade, junior high school, senior high school, and university levels, respectively. The CRF of boys at almost all ages showed a continuous decreasing trend from 1985 to 2014, except for the seven-year-old boys, whose CRF rebounded from 2005 to 2014 . From 1985 to 2005, the CRF of girls at all ages showed a decreasing trend, but from 2005 to 2014, the CRF of girls at almost all ages rebounded, except for those aged 19 in college. The biggest decline in CRF for both boys and girls occurred at age 13. The time taken to run $1000 \mathrm{~m}$ and $800 \mathrm{~m}$ increased by $37.1 \mathrm{~s}$ and $30.7 \mathrm{~s}$, respectively, during the 30-year period.

Table 3. Running Time for Children and Adolescents (s), 1985-2014

\begin{tabular}{cccccc}
\hline Sex (years) & $\mathbf{7}$ & $\mathbf{1 2}$ & $\mathbf{1 3}$ & $\mathbf{1 6}$ & $\mathbf{1 9}$ \\
\hline Male & & & & & \\
1985 & 125.48 & 104.58 & 265.57 & 240.90 & 232.91 \\
1991 & 128.40 & 106.18 & 268.74 & 246.64 & 234.83 \\
1995 & 128.11 & 107.35 & 272.41 & 246.33 & 233.93 \\
2000 & 135.77 & 115.70 & 283.42 & 253.73 & 245.26 \\
2005 & 137.88 & 116.18 & 299.52 & 266.31 & 258.41 \\
2010 & 136.63 & 114.69 & 296.92 & 265.66 & 259.02 \\
2014 & 136.60 & 115.71 & 302.67 & 267.51 & 264.18 \\
\hline Female & & & & & \\
1985 & 131.44 & 112.30 & 238.84 & 241.15 & 234.47 \\
1991 & 133.40 & 113.13 & 241.74 & 243.64 & 235.99 \\
1995 & 132.63 & 114.14 & 243.50 & 243.50 & 233.29 \\
2000 & 140.08 & 123.91 & 260.00 & 253.56 & 247.38 \\
2005 & 141.03 & 125.11 & 273.24 & 264.36 & 254.24 \\
2010 & 139.94 & 121.66 & 270.98 & 263.24 & 257.57 \\
2014 & 140.27 & 121.68 & 269.54 & 263.74 & 255.84 \\
\hline
\end{tabular}

$50 \mathrm{~m} \times 8$ for boys and girls (7-12 years), $1000 \mathrm{~m}$ for boys (13-22 years), and $800 \mathrm{~m}$ for girls (13-22 years).

\subsection{Empirical Analysis}

The fixed effects model regression was applied to all models. The fixed effects model was chosen because time-invariant variables were not included in the study. It offers the advantage of not assuming the relationship between the error term and the explanatory variable [26]. On the basis of the natural logarithm of each variable, robust command was used to correct the standard error with white heteroscedasticity to ensure robust results. The subsequent regressions eliminated the outliers.

\subsubsection{Linear Analysis}

Columns (linear) in Tables 4 and 5 represent the estimated results for Equation (1), which show the performance of linear specification between economic growth in China and CRF of children and adolescents after controlling for other variables, such as urbanization rate and CPI. In Table 4, the 
coefficients of LPCDI for the CRF of boys and girls (7-12-year-old) are -0.006 and -0.001 , small and not significant $(p>0.1)$, indicating that there is no linear relationship between PCDI and CRF of children living in urban areas. Table 5 shows that the model yielded a significantly positive coefficient of LPCDI for boys (13-22-year-old): -0.027 . Given the log-log specification, the coefficients represent the elasticity of the mean running time with respect to PCDI. A $1 \%$ increase in per capita PCDI is accompanied by a decrease in mean running time by $0.027 \%$ for boys (aged $13-22$ years). This finding implies that PCDI has a positive impact on the cardiopulmonary fitness of boys (aged 13-22 years), contrary to the descriptive results in Table 3, and theoretical reasoning. This seems to be related to the fact that part of the decrease in CRF is attributed to a positive time trend for any nationwide factor (e.g., national economic development and national policies) that could affect CRF. The elasticity of the impact of PCDI on CRF of urban girls (aged 13-22 years) is -0.022 and not significant $(p>0.1$ ), indicating that the relationship between PCDI and CRF of urban girls (aged 13-22 years) is not linear.

Table 4. Econometric Estimates of the Relationship Between PCDI and CRF of Children.

\begin{tabular}{ccccc}
\hline \multirow{2}{*}{ Variable } & \multicolumn{2}{c}{ L50 $\times \mathbf{8}$} & \multicolumn{3}{c}{ L50 $\times \mathbf{8}$} \\
\cline { 2 - 5 } & Linear (Male) & Quadratic (Male) & Linear (Female) & Quadratic (Female) \\
\hline LPCDI & -0.006 & $0.328^{* * *}$ & -0.001 & $0.347^{* * *}$ \\
& $(-0.35)$ & $(5.45)$ & $(-0.07)$ & $(6.14)$ \\
LPCDI ${ }^{2}$ & & $-0.018^{* * *}$ & & $-0.019^{* * *}$ \\
& & $(-5.71)$ & & $(-6.38)$ \\
LURBAN & $-0.020^{* * *}$ & $-0.013^{* *}$ & $-0.021^{* * *}$ & $-0.014^{* *}$ \\
& $(-2.77)$ & $(-2.03)$ & $(-2.93)$ & $(-2.13)$ \\
LCPI & $0.204^{* *}$ & 0.025 & $0.211^{* *}$ & 0.024 \\
& $(2.50)$ & $(0.35)$ & $(2.41)$ & $(0.30)$ \\
cons & $3.872^{* * *}$ & $3.302^{* * *}$ & $3.866^{* * *}$ & $3.270^{* * *}$ \\
& $(8.79)$ & $(7.11)$ & $(8.49)$ & $(6.81)$ \\
$\mathrm{R}^{2}$ & 0.547 & 0.565 & 0.466 & 0.491 \\
$\mathrm{~F}$ & 159.471 & 147.363 & 106.812 & 100.308 \\
$P$ & 0.000 & 0.000 & 0.000 & 0.000 \\
$N$ & 1134 & 1134 & 1134 & 1134 \\
\hline
\end{tabular}

L50 $\times 8, \log$ of running time for $50 \mathrm{~m} \times 8$; LPCDI, log of real per capita disposable income; $\mathrm{LPCDI}^{2}$, the squared term of LPCDI. LURBAN, $\log$ of urbanization rate; LCPI, $\log$ of consumer price index; The White (1980) robust regression. t statistics in parentheses. ${ }^{*}, * *$ and ${ }^{* * *}$ denote statistical significance at the $10 \%, 5 \%$, and $1 \%$ levels, respectively.

Table 5. Econometric Estimates of the Relationship Between PCDI and CRF of adolescents.

\begin{tabular}{ccccc}
\hline \multirow{2}{*}{ Variable } & \multicolumn{2}{c}{ L1000 } & \multicolumn{2}{c}{ L800 } \\
\cline { 2 - 5 } & Linear (Male) & Quadratic (Male) & Linear (Female) & Quadratic (Female) \\
\hline LPCDI & $-0.027^{* *}$ & $0.093^{* *}$ & -0.022 & $0.116^{* *}$ \\
& $(-2.25)$ & $(2.05)$ & $(-1.53)$ & $(2.52)$ \\
LPCDI $^{2}$ & & $-0.007^{* * *}$ & & $-0.008^{* * *}$ \\
& & $(-2.72)$ & & $(-3.07)$ \\
LURBAN & -0.001 & 0.001 & 0.000 & 0.003 \\
& $(-0.23)$ & $(0.20)$ & $(0.05)$ & $0.45)$ \\
LCPI & 0.010 & -0.054 & 0.124 & 0.049 \\
& $(0.15)$ & $(-0.82)$ & $(1.50)$ & $(0.59)$ \\
cons & $5.628^{* * *}$ & $5.423^{* * *}$ & $5.045^{* * *}$ & $4.808^{* * *}$ \\
& $(16.17)$ & $(14.44)$ & $(11.86)$ & $(10.94)$ \\
$\mathrm{R}^{2}$ & 0.615 & 0.617 & 0.514 & 0.518 \\
$\mathrm{~F}$ & 226.681 & 225.073 & 138.782 & 131.749 \\
$P$ & 0.000 & 0.000 & 0.000 & 0.000 \\
$N$ & 1890 & 1890 & 1890 & 1890 \\
\hline
\end{tabular}

L1000, log of running time for $1000 \mathrm{~m}$ (boys); L800, log of running time for $800 \mathrm{~m}$ (girls); LPCDI, log of real per capita disposable income; LPCDI $^{2}$, the squared term of LPCDI. LURBAN, log of urbanization rate; LCPI, $\log$ of consumer price index; The White (1980) robust regression. t statistics in parentheses. * ${ }^{* *}$ and ${ }^{* * *}$ denote statistical significance at the $10 \%, 5 \%$, and $1 \%$ levels, respectively. 


\subsubsection{Quadratic Model}

To further explore trends of influence of economy on students' CRF levels, the square term of LPCDI was added to test the marginal effect [26]. Columns (quadratic) in Tables 4 and 5 show the results of the nonlinear relationship test between economic growth and CRF of children and adolescents, as estimates of Model (2). The results show that $\beta 1>0$ and $\beta 2<0$ and both are statistically significant, indicating that PCDI has an inverted U-shaped relationship with the mean running test time, that is, it has a U-shaped relationship with cardiopulmonary endurance levels, especially for children, boys $(\beta 1=0.328(p<0.01) ; \beta 2=-0.018(p<0.01))$ and girls $(\beta 1=0.347(p<0.01) ; \beta 2=-0.019(p<0.01))$. It appears that as incomes increased, the CRF of urban male and female students gradually decreased to the lowest point, after which it showed an upward trend. From a horizontal perspective, it can be inferred that for less-developed provinces, increases in incomes cause a decrease in CRF levels; subsequently increasing health risks. In contrast, for highly developed provinces, as incomes increase, CRF increases.

\section{Discussion}

This study shows a pattern of CRF-Kuznets curve, a U-shaped relationship between economy and CRF of children and adolescents based on provincial data from 1985-2014. The analysis reveals that the negative impact of economic development on cardiorespiratory fitness of children and adolescents gradually decreased over the years. Similarly, another study found a non-linear relationship between a country's income per capita and weight-related health status (Obesity Kuznets curve) for men and women according to the country-level panel data of 130 countries from 1975 to 2010 [28]. The Obesity Kuznets curve has also been reported for state-level panel data from 1991-2010 [29]. However, few studies have explored the relationship between macroeconomics and cardiopulmonary fitness.

Our results reveal that as an economy grows, the cardiorespiratory fitness level of students aged 7-22 years gradually decreases; this decline tends to slow down and stagnate at some point. Indeed, from 1984 to 2014, the CRF of Chinese urban students showed a U-shaped trajectory. From 1984 to 2005, national survey reports on students' physical health showed that the CRF of children and adolescents continuously decreased [22,30,31], as shown in Table 3. However, in 2010, a national survey on student physical fitness showed that the continuous decline in CRF of primary and middle school students had been contained [32]. This is because running time of the $50 \mathrm{~m} \times 8$ was shorter by $0.05 \mathrm{~s}$ on average for girls and unchanged for boys aged 7-12 years, compared to 2005. The running time of boys and girls aged 13-15 years in junior middle schools decreased by $3.03 \mathrm{~s}$ and $3.58 \mathrm{~s}$ on average, respectively. The average performance of boys and girls aged 16-18 years decreased by $0.48 \mathrm{~s}$ and $0.46 \mathrm{~s}$, respectively, compared with 2005 [32], as shown in Tables 2 and 3. A national student physical fitness survey conducted in 2014 showed that the cardiorespiratory fitness of primary and middle school students remained stable [33].

The decrease in CRF of children and adolescents from 1984 to 2005 may be explained by the following factors. First, over-nutrition affects cardiorespiratory endurance. A study found that the CRF of overweight and obese students was significantly lower than that of students with normal weight [27]. Moreover, a higher BMI is associated with decreased cardiorespiratory endurance levels [27]. This indicates that being overweight and obese negatively affects CRF of students. It is conceivable that the decline in Chinese students' CRF over the past 30 years is due to an increase in overweight and obesity rates. In addition, students' sedentary lifestyles may affect their cardiopulmonary fitness [34,35]. Owing to rapid developments in science and technology, China has entered an era of automation - private cars, buses, subways, and other means of transportation have decreased walking. The diversification and modernization of modes of transport have decreased participation in physical activity among teenagers, leading to underutilization of human energy [36]. In addition, the exam-oriented education system and high academic demands have reduced the amount of leisure time for students. In addition, several students tend to choose electronic games over physical activity for leisure [37]. These factors are likely to affect CRF of students. 
However, data has shown that from 2005 to 2014, the deterioration in cardiorespiratory endurance levels of students has been contained, especially for middle and high school students. This can be explained by the following reasons: First, several community sports facilities, national fitness centers, fitness paths, fitness squares, and parks have been built, providing teenagers with better platforms to engage in physical activity [38]. Second, family incomes and parents' education levels have also increased. Some studies have shown that the education level, health awareness, and financial support of parents have a positive impact on children's and adolescents' participation in physical activity or physical education [39-41]. This is because as the social economy develops and living standards improve, people tend to pay more attention to physical and mental health, especially with respect to children.

This study examined the relationship between economic development and CRF of children and adolescents. This analysis is based on one million data collected from surveys conducted in five-year interval periods between 1985 and 2014 covering 27 provinces in China. We show that the relationship between economic development and CRF of children and adolescents is U-shaped. For low-income provinces, increases in income causes a decrease in the CRF-related health status. In contrast, for high-income provinces, as incomes increase, the CRF-related health status improves. Our findings support the possibility that youths living in middle-income provinces may be at risk of poor health, which calls for health policies targeting prevention and intervention in China and other developing countries.

The findings of this study may be affected by endogeneity. Another limitation is that cardiorespiratory fitness was measured by a long-distance running test, which may be affected by several factors, such as environmental conditions and running surfaces. However, in order to collect time series data for further studies, physical fitness in China was measured over a long period. Previous studies suggest that running tests are valid and reliable. The main strength of this study is the large sample size used, based on five-year assessments of CRF for children and adolescents aged 7-22 years over a 30-year period. This study also provides evidence of the impact of social environmental factors (such as economy and policy) on cardiorespiratory fitness of children and adolescent based on panel data.

Future multi-level studies based on the theory of social ecological model should be conducted. Other studies should explore the impact of national economy on the health of rural Chinese students, to compare cardiorespiratory fitness between urban and rural areas. In order to formulate more effective and scientific intervention measures, studies should be conducted from a socio-ecological microsystem perspective, such as correlation and collaboration among schools, communities, and families.

\section{Conclusions}

The main finding of this study is that a U-shaped relationship exists between China's economic development and the cardiorespiratory fitness of children and adolescents. The negative effect of economic development on cardiorespiratory fitness of urban students is seen to decrease and eventually reach stagnation, especially in highly developed provinces. This analysis provides evidence that students living in middle-income provinces may be at risk of developing health problems, calling for effective health policies targeting prevention and intervention.

Author Contributions: All authors read and approved the final manuscript. X.G. designed the study, collected the data, participated in statistical analysis and drafted the manuscript. K.Y. and X.W. designed the study, collected the data and participated in statistical analysis. Y.J. played a role in data collection.

Funding: This study is funded by the National Social Science Foundation key program project (funding number 17ATY009). Its content is solely the responsibility of the authors and does not necessarily represent the official views of the funders.

Conflicts of Interest: The authors declare no conflict of interest. 


\section{References}

1. Kodama, S.; Saito, K.; Tanaka, S.; Maki, M.; Yachi, Y.; Asumi, M.; Sugawara, A.; Totsuka, K.; Shimano, H.; Ohashi, Y.; et al. Cardiorespiratory Fitness as a Quantitative Predictor of All-Cause Mortality and Cardiovascula Events in Healthy Men and Women: A Meta-analysis. JAMA 2009, 301, 2024-2035. [CrossRef]

2. Sawada, S.S.; Lee, I.M.; Naito, H.; Kakigi, R.; Goto, S.; Kanazawa, M.; Okamoto, T.; Tsukamoto, K.; Muto, T.; Tanaka, H.; et al. Cardiorespiratory fitness, body mass index, and cancer mortality: A cohort study of Japanese men. BMC Public Health 2014, 14, 1012. [CrossRef] [PubMed]

3. Katzmarzyk, P.T.; Church, T.S.; Janssen, I.; Ross, R.; Blair, S.N. Metabolic syndrome, obesity, and mortality: Impact of cardiorespiratory fitness. Diabetes Care 2005, 28, 391-397. [CrossRef]

4. Kohl, H.W.; Craig, C.L.; Lambert, E.V.; Inoue, S.; Alkandari, J.R.; Leetongin, G.; Kahlmeier, S. Lancet Physical Activity Series Working Group. The pandemic of physical inactivity: Global action for public health. Lancet 2012, 380, 294-305. [PubMed]

5. Tomkinson, G.R.; Léger, L.A.; Olds, T.S.; Cazorla, G. Secular Trends in the Performance of Children and Adolescents (1980-2000). Sports Med. 2003, 33, 285-300. [CrossRef] [PubMed]

6. Tomkinson, G.R.; Olds, T.S.; Kang, S.J.; Kim, D. Y Secular trends in the aerobic fitness test performance and body mass index of Korean children and adolescents (1968-2000). Int. J. Sports Med. 2006, 28, 314-320. [CrossRef] [PubMed]

7. Huotari, P.R.; Nupponen, H.; Laakso, L.; Kujala, U.M. Secular trends in aerobic fitness performance in 13-18-year-old adolescents from 1976 to 2001. Br. J. Sports Med. 2010, 44, 968-972. [CrossRef]

8. Dyrstad, S.M.; Berg, T.; Tjelta, L.I. Secular trends in aerobic fitness performance in a cohort of Norwegian adolescents. Scand. J. Med. Sci. Sports 2012, 22, 822-827. [CrossRef]

9. Nelson, M.C.; Neumark-Stzainer, D.; Hannan, P.J.; Sirard, J.R.; Story, M. Longitudinal and secular trends in physical activity and sedentary behavior during adolescence. J. Am. Diet. Assoc. 2006, 106, A66. [CrossRef]

10. Terangarcia, M.; Rankinen, T.; Bouchard, C. Genes, exercise, growth, and the sedentary, obese child. J. Appl. Physiol. 2008, 105, 988-1001. [CrossRef]

11. Pratt, M.; Sarmiento, O.L.; Montes, F.; Ogilvie, D.; Marcus, B.H.; Perez, L.G.; Brownson, R.C. Lancet Physical Activity Series Working Group. The implications of megatrends in information and communication technology and transportation for changes in global physical activity. Lancet 2012, 380, 282-293. [CrossRef]

12. Doi, S.A.R.; Williams, G.M. Methods of Clinical Epidemiology; Springer Science \& Business Media: Berlin, Germany, 2013.

13. Tomkinson, G.R.; Lang, J.J.; Tremblay, M.S. Temporal trends in the cardiorespiratory fitness of children and adolescents representing 19 high-income and upper middle-income countries between 1981 and 2014. Br. J. Sports Med. 2017, 53, 478-486. [CrossRef] [PubMed]

14. Lang, J.J.; Tremblay, M.S.; Léger, L.; Olds, T.; Tomkinson, G.R. International variability in $20 \mathrm{~m}$ shuttle run performance in children and youth: Who are the fittest from a 50-country comparison? A systematic literature review with pooling of aggregate results. Br. J. Sports Med. 2018, 52, 276. [PubMed]

15. Attard, S.M.; Howard, A.G.; Herring, A.H.; Zhang, B.; Du, S.; Aiello, A.E.; Popkin, B.M.; Gordon-Larsen, P. Differential associations of urbanicity and income with physical activity in adults in urbanizing China: Findings from the population-based China Health and Nutrition Survey 1991-2009. Int. J. Behav. Nutr. Phys. Act. 2015, 12, 152. [CrossRef] [PubMed]

16. Day, K. Built environmental correlates of physical activity in China: A review. Prev. Med. Rep. 2016, 3, 303-316. [CrossRef] [PubMed]

17. Xu, F.; Li, J.; Liang, Y.; Wang, Z.; Hong, X.; Ware, R.S.; Leslie, E.; Sugiyama, T.; Owen, N. Associations of Residential Density with Adolescents' Physical Activity in a Rapidly Urbanizing Area of Mainland China. J. Urban Health Bull. New York Acad. Med. 2010, 87, 44-53. [CrossRef] [PubMed]

18. CNSSCH. Association Report on the 1985th National Survey on Students' Constitution and Health; People's Educational Publication: Beijing, China, 1987.

19. CNSSCH. Association Report on the 1991th National Survey on Students' Constitution and Health; Beijing Technical and Science Press: Beijing, China, 1993.

20. CNSSCH. Association Report on the 1995th National Survey on Students' Constitution and Health; Jilin Technical and Science Publication: Changchun, China, 1997. 
21. CNSSCH. Association Report on the 2000th National Survey on Students' Constitution and Health; China College \& University Press: Beijing, China, 2002.

22. CNSSCH. Association Report on the 2005th National Survey on Students' Constitution and Health; China College \& University Press: Beijing, China, 2007.

23. CNSSCH. Association Report on the 2010th National Survey on Students' Constitution and Health; China College \& University Press: Beijing, China, 2012.

24. CNSSCH. Association Report on the 2014th National Survey on Students' Constitution and Health; China College \& University Press: Beijing, China, 2016.

25. Statistical Yearbook of China's Provinces (1985, 1995, 2000, 2005, 2010 and 2014). Available online: http://data.cnki.net/Yearbook (accessed on 19 June 2019).

26. Wooldridge, J. Introductory Econometrics: A Modern Approach, 5th ed.; Tsinghua University Press: Beijing, China, 2014.

27. Li, X.H.; Ma, J.; Wang, H.J. Analysis of influencing factors of endurance of Chinese middle and primary school students aged 10-17 years. Chin. J. Prev. Med. 2013, 47, 700-706.

28. Windarti, N.; Hlaing, S.W.; Kakinaka, M. Obesity Kuznets curve: International evidence. Public Health 2019, 169, 26-35. [CrossRef] [PubMed]

29. Grecu, A.M.; Rotthoff, K.W. Economic Growth and Obesity: Findings of an Obesity Kuznets Curve. Appl. Econ. Lett. 2015, 22, 539-543. [CrossRef]

30. Liao, W.K. A national survey on students' physical health in 1995. Chin. J. Prev. Med. 1997, 31, 42-43.

31. Yang, G.R. A national survey on students' physical health in 2000. Chin. J. Sch. Health 2002, 23, 2-3.

32. CNSSCH. A national survey on students' physical fitness and health in 2010. Chin. J. Sch. Health 2011, 32, 3.

33. CNSSCH. A national survey on students' physical fitness and health in 2014. Chin. J. Sch. Health 2015, 36, 3.

34. Nelson, M.C.; Gordon-Larsen, P.; Adair, L.S.; Popkin, B.M. Adolescent physical activity and sedentary behavior: Patterning and long-term maintenance. Am. J. Prev. Med. 2005, 28, 259-266. [CrossRef] [PubMed]

35. Lowry, R.; Michael, S.; Demissie, Z.; Kann, L.; Galuska, D.A. Associations of Physical Activity and Sedentary Behaviors with Dietary Behaviors among US High School Students. J. Obes. 2015, 2015, 876524. [CrossRef] [PubMed]

36. Lin, L.; He, L. Overweight, Commuting to School, Urban Design in Chinese School Neighborhoods. J. Transp. Health 2016, 3, S19. [CrossRef]

37. Tudor-Locke, C.; Ainsworth, B.E.; Adair, L.S.; Du, S.; Popkin, B.M. Physical activity and inactivity in Chinese school-aged youth: The China Health and Nutrition Survey. Int. J. Obes. Relat. Metab. Disord. J. Int. Assoc. Study Obes. 2003, 27, 1093. [CrossRef] [PubMed]

38. Cui, R.H.; Wang, Z.Y. Analysis of coordination between construction of public sports facilities and economic development in liaoning province. J. Wuhan Inst. Phys. Educ. 2012, 46, 13-18.

39. Liu, Y.; Zhang, Y.; Chen, S.; Zhang, J.; Guo, Z.; Chen, P. Associations between parental support for physical activity and moderate-to-vigorous physical activity among Chinese school children: A cross-sectional study. J. Sport Health Sci. 2017, 6, 410-415. [CrossRef]

40. Stalsberg, R.; Pedersen, A.V. Effects of socioeconomic status on the physical activity in adolescents: A systematic review of the evidence. Scand. J. Med. Sci. Sports 2010, 20, 368-383. [CrossRef]

41. Sherar, L.B.; Griffin, T.P.; Ekelund, U.; Cooper, A.R.; Esliger, D.W.; van Sluijs, E.M.; Andersen, L.B.; Cardon, G.; Davey, R.; Froberg, K.; et al. Association between maternal education and objectively measured physical activity and sedentary time in adolescents. J. Epidemiol. Community Health 2016, 70, 541-548. [CrossRef] [PubMed]

(C) 2019 by the authors. Licensee MDPI, Basel, Switzerland. This article is an open access article distributed under the terms and conditions of the Creative Commons Attribution (CC BY) license (http://creativecommons.org/licenses/by/4.0/). 